\title{
Factors Associated with Adherence to Clinical Practice Guidelines for Patients with Type 2 Diabetes Mellitus: Results of a Spanish Delphi Consensus
}

\author{
José Antonio Gimeno ${ }^{1},{ }^{1}$ Gloria Cánovas, ${ }^{2}$ and Alejandra Durán ${ }^{3}$ \\ ${ }^{1}$ Service of Endocrinology, Hospital Clínico Lozano Blesa, Zaragoza, Spain \\ ${ }^{2}$ Service of Endocrinology, Hospital de Fuenlabrada, Madrid, Spain \\ ${ }^{3}$ Service of Endocrinology, Hospital Clínico San Carlos, Madrid, Spain \\ Correspondence should be addressed to José Antonio Gimeno; jagimeno@salud.aragon.es
}

Received 4 March 2021; Accepted 10 August 2021; Published 23 October 2021

Academic Editor: Jordi Lluis Reverter

Copyright (C) 2021 José Antonio Gimeno et al. This is an open access article distributed under the Creative Commons Attribution License, which permits unrestricted use, distribution, and reproduction in any medium, provided the original work is properly cited.

\begin{abstract}
Objective. To assess factors associated with adherence to clinical practice guidelines (CPGs) for type 2 diabetes mellitus (T2DM). Methods. A cross-sectional multicenter study based on a two-round Delphi survey was designed. A total of 98 endocrinologists (mean age 45 years) involved in the care of T2DM patients completed a 43-item questionnaire assessing different aspects of adherence related to CPGs. Results. Most participants worked in tertiary care public hospitals. All participants used CPGs, with ADA/EASD as the most common (99\%). The lack of time, establishment of an individualized management of patients, insufficient human resources, and therapeutic inertia were scored as the main reasons for not following CPGs recommendations. Participants agreed that insufficient material resources and limitations established by the healthcare system prevent adherence to CPGs. The risk of hypoglycemia was considered to be limiting factor for the patients' integral control. Also, there was consensus on the need to have the support of nursing personnel with specific training in diabetes as well as dietitians and podiatrists. There was disagreement regarding the influence on adherence to CPGs of patient's characteristics not matching those of CPGs, patient's preferences, tolerability of the action recommended, concomitant comorbidities, or pluripathological conditions. Differences according to the participant's age ( $\leq 40$ years vs. $>40$ years) were not found. Therapeutic inertia and lack of time did not show a significant correlation. Conclusions. Nonadherence to CPGs on T2DM is a multifactorial problem but the existence multiple CPGs, the lack of time, the therapeutic inertia, and insufficient human resources have been identified as factors limiting adherence. Hypoglycemia continues to be a barrier for achievement of targets recommended by CPGs.
\end{abstract}

\section{Introduction}

Diabetes mellitus $(\mathrm{DM})$ is a complex multisystemic disease that requires high quality care, increases the risk of potentially life-threatening complications, and imposes a high impact on healthcare services and a heavy economic burden on society [1-3]. According to estimates of the global prevalence of diabetes for 2000, projections extrapolated for 2030 to all 191 World Health Organization (WHO) member states, the prevalence of the disease is projected to rise from $2.8 \%$ to $4.4 \%$, the total number of people with DM from
171 million to 366 million, with an increase in the proportion of diabetic people $>65$ years, and the urban population with DM in developing countries to double [4]. Therefore, in the presence of these negative perspectives, strategies for improving effective diagnosis and management of subjects with DM are of utmost importance.

The pathogenesis and long-term metabolic and vascular complications of type 2 diabetes (T2DM) are fairly well known but its treatment has remained challenging, with only half of the patients achieving the recommended HbAlc target, and a significant proportion of the diabetic population 
still do not receiving adequate care [5]. Clinical practice guidelines (CPGs) provide comprehensive evidence-based recommendations based on randomized controlled trials (RCTs) for all relevant aspects of DM, including diagnosis and treatment of type 1 and type 2 in children and adults, strategies for the prevention or delay of T2DM, and therapeutic approaches that can reduce morbidity, in particular, the risk of renal and cardiovascular complications, and improve patient outcomes [6-11]. It has been clearly shown that the use of guidelines is associated with better prognosis, achieving target goals for $\mathrm{HbAlc}$, blood pressure, renal function, and lipid profiles, as well as greater patient's satisfaction than when they are not used [12-14]. However, the adherence of healthcare professionals to recommendations of CPGs is unsatisfactory, with deficiencies in most areas of diabetes care and follow-up [15-19]. Barriers reported include lack of awareness, familiarity or agreement with the content, poor understanding of the need for change to overcome the inertia of normal practice, differences in the goals between clinicians and patients, and a number of external constraints associated with deficiencies in equipment and space, shortage of time, staff, and financial resources [20-23]. It has been emphasized that it is essential to recognize the factors that act as barriers and contribute to the missing link between theory and practice of diabetic guidelines [24], which will help to design and implement appropriate strategies for effective and improved diabetes guidelines adherence and management.

To address these issues, this study was designed with the primary objective of assessing factors involved in adherence to CPGs on T2DM diabetes. Secondary objectives were to identify major barriers preventing adherence to main CPGs and to develop a document with conclusions regarding actions for improving adherence to guidelines, which will finally contribute to a more effective care of patients with T2DM.

\section{Methods}

2.1. Study Design. This was a cross-sectional multicenter study based on a two-round Delphi survey (the IMPLICA study). IMPLICA is the Spanish acronym for "Factores IMPLicados en el seguimiento de las guías de páctIca Clínica en diAbetes" (factors involved in adherence to clinical practice guidelines in diabetes). The study was conducted over two 3-month periods (first Delphi round from April to June, 2020; second Delphi round from August to October, 2020). The study protocol was approved by the Ethics Committee for Clinical Research of Hospital Clínico San Carlos, Madrid (Spain).

2.2. Participants and Procedures. A panel of three clinically active specialists in endocrinology, metabolism, and nutrition with special interest and large experience in the care of patients with diabetes was recruited to form the scientific committee of the study. They were responsible for the development of the study questionnaire and supervision of the progression of the study, including the recruitment of participants, coordination of the analysis, and interpretation of data. The content and topics to be included in the study questionnaire were designed by the scientific committee based on their experience and a comprehensive search of the literature to identify previously conducted studies with high level of evidence and key primary studies focused on the care of subjects with 2TDM and, particularly, on CPGs and adherence to recommendations.

Study participants were experienced practicing specialists in endocrinology, metabolism, and nutrition attending a minimum of 10 patients with T2DM every week in either public or private institutions throughout Spain. Participants were recruited through formal e-mail invitations that included a brochure with full information about the project. Participation in the study was anonymous. The questionnaire was lodged in an Internet microsite that could be accessed via a weblink included in the brochure. Only physicians who accepted to participate in the study were provided with access to the questionnaire microsite URL and the user's password. Participation in the study was anonymous and voluntary.

The final questionnaire emerged from a two-round Delphi consensus process and was composed of 8 sections with a total of 43 items. Section 1 (5 items) included data of the investigator and use of CPGs on diabetes, Section 2 (7 items) data on the participant's healthcare center and volume of diabetic patients attended, Section 3 (13 items) factors related to CPGs, Section 4 (3 items) factors related to the healthcare system, Section 5 (3 items) factors related to the healthcare center, Section 6 ( 2 items) factors related to diabetes, Section 7 (6 items) factors related to the clinician, and Section 8 (7 items) factors related to the patient. There were open questions, multiple choice questions, and some other questions formulated so that they could be answered using a 5-point Likert scale from $1=$ "strongly disagree," $2=$ "moderately disagree," 3 = "neither agree nor disagree" (indifferent), $4=$ "moderately agree," and $5=$ "strongly agre $e$, according to the participant's opinion. The study questionnaire is described in the Supplementary material (available here).

2.3. Statistical Analysis. For each item of the study questionnaire, the mean value of the five possible responses in the 5-point Likert scale was calculated. A consensus was established in favor of the recommendation when the sum of responses "strongly agree" (Likert score 5), and "moderately agree" (Likert score 4 ) was greater than $75 \%$ of the total responses obtained for that item. By contrast, a consensus against the recommendation was reached when the sum of responses "strongly disagree" (Likert score 2) and "moderately disagree" (Likert score 1) was greater than $75 \%$ of the total responses for that item. When none of these previous assumptions were met, a consensus for or against the statement was not reached. Since this was a qualitative rather than a quantitative study, the number of selected participants based on the probabilistic error was not established [25, 26]. Categorical variables are expressed as frequencies and percentages and continuous data as mean and standard deviation (SD) or median and interquartile range (25th-75th percentile). Participants were divided according to age in 
the groups of $\leq 40$ years and $>40$ year, and differences in the distribution of variables were analyzed with the Mann-Whitney $U$ test for independent samples. The relationship between the lack of time in consultations and the therapeutic inertia was assessed with Spearman's rank-order correlation coefficient $(\rho)$. Data were analyzed using the SAS statistical program (Statistical Analysis Systems, SAS Institute, Cary, NC, USA) version 9.1.3 for Windows.

\section{Results}

3.1. Participants and Use of CPGs. A total of 98 endocrinologists (40 men, 58 women) with a mean (SD) age of 44.9 (9.2) years (range 29-65) agreed to participate in the study. They had been practicing for a mean (SD) of 16.0 (9.5) years. Almost all participants (90.8\%) worked in public hospitals (tertiary care hospitals in 75\%) located in urban areas (99\%), with a median of 9 endocrinologists working in their services. Participation in a training program on diabetes and in a research program in the previous 12 months was reported by $78.6 \%$ and $53.1 \%$ of participants, respectively. Also, $67.3 \%$ reported that they had attended between 76 and 150 patients in the last week, and that more than $25 \%$ of patients were diagnosed with T2DM according to $69.4 \%$ of participants.

All participants used CPGs in the care of patients with T2DM, with the American Diabetes Association/European Association for the Study of Diabetes (ADA/EASD) recommendations as the most commonly used guideline (99\%), followed by the document of integral approach of T2DM of the Spanish Society of Endocrinology and Nutrition (SEEN) by $79.6 \%$, the American Association of Clinical Endocrinologists/American College of Endocrinologists (AACE/ACE) comprehensive type 2 diabetes management algorithm by $38.8 \%$, the recommendations for the pharmacological treatment of hyperglycemia in T2DM of the Spanish Society of Diabetes (SED) by $34.7 \%$, the T2DM in adults: management NICE by $10.2 \%$, and the Clinical Practice Guidelines for the Prevention and Management of Diabetes in, Canada, Professional Section of Diabetes Canada by $8.2 \%$. As shown in Figure 1, the lack of time, establishment of an individualized management of patients, insufficient human resources, and therapeutic inertia were scored as the main reasons for not following the recommendations of CPGs.

3.2. Factors Related to the CPG. Consensus was achieved in 7 of 10 items included in this section (percentages of agreement from $80.2 \%$ to $98 \%$ ) (Table 1 ). The remaining three items in which consensus was not obtained were "the evolution of the research, given that sometimes there are subsequent findings that are proven uncertain or irreproducible, may reduce the credibility of the CPG recommendations," "the complexity of the process recommended in the CPG difficults adherence," and "although a guide is well implemented it is difficult to maintain it, since after a certain time professionals tend to return to their previous routines" with percentages of agreement of $74 \%, 43,8 \%$, and $25 \%$, respectively. Lack of time, the need to establish individualized treatment, insufficient human resources, therapeutic inertia, and insufficient material resources were the most common factors associated with nonadherence to CPGs (Figure 1).

\subsection{Factors Related to the Healthcare System and Healthcare} Center. Participants agreed that limitations established by the healthcare system prevent adherence to CPGs (75\%), and that differences in local administrative regulations between autonomous communities have a different impact on adherence (90.9\%) (Table 2). The statement of the lack of coincidence between recommendations of international CPGs and the current situation of the healthcare systems did not achieved consensus $(42.7 \%)$. In relation to the influence of conditions of the healthcare center, availability of time $(92.7 \%)$ and human resources $(86.5 \%)$ were considered to affect adherence, whereas participants did not agree on the influence on the shortage of adequate material resources for diagnosis and treatment of T2DM (54.2\%) (Table 2).

3.4. Factors Related to Diabetes and the Clinician. As shown in Table 3, participants disagreed that complexity of diabetes affected adherence to CPGs (63.5\%) but agreed that the risk of hypoglycemia continues to be a limiting factor for the patients' integral control $(83.4 \%)$. In relation to the factors associated with the clinician, consensus was reached in 3 of the 6 items (50\%), which included the following: "therapeutic inertia means that despite knowing the CPG recommendations, the clinician continues with his previous practice" $(83.3 \%)$, "the need to have the support of dietitians and podiatrists" (95.9\%), and "the insufficient number of nursing personnel with specific training in diabetes education makes it difficult to approach patients with T2DM" (95.9\%). Neither regular updating of CPG, nor complexity of the pathology or pharmacological treatment nor problems derived from the lack of connection between all members of the interdisciplinary team, achieved consensus (Table 3).

3.5. Factors Related to the Patient. In this section of 7 items, consensus was achieved in only 2 (28.6\%) (Figure 2), including that complexity of treatment difficults therapeutic adherence (90.7\%) and patient's difficulties to follow hygienic-dietetic and lifestyle recommendations prevented to achieve therapeutic objectives (92.8\%). In relation to other factors including patient's characteristics not matching those of CPGs, patient's preferences, tolerability of the action recommended, concomitant comorbidities, or pluripathological conditions, participants disagreed on their influence on adherence to CPGs (Figure 2).

Finally, there were no statistically significant differences in the responses obtained according to the participant's age of $\leq 40$ years $(n=37)$ and $>40$ years $(n=61)$ in eight items selected by the scientific committee, which included "the complexity of the process recommended in the CPG difficults adherence" and "the large number of CPGs on diabetes may prevent effective dissemination" as two factors related to the CPG (Table 1); "insufficient material resources for diagnosis and treatment recommended by CPGs" as one factor related to the healthcare center (Table 2); "complexity of diabetes difficults 


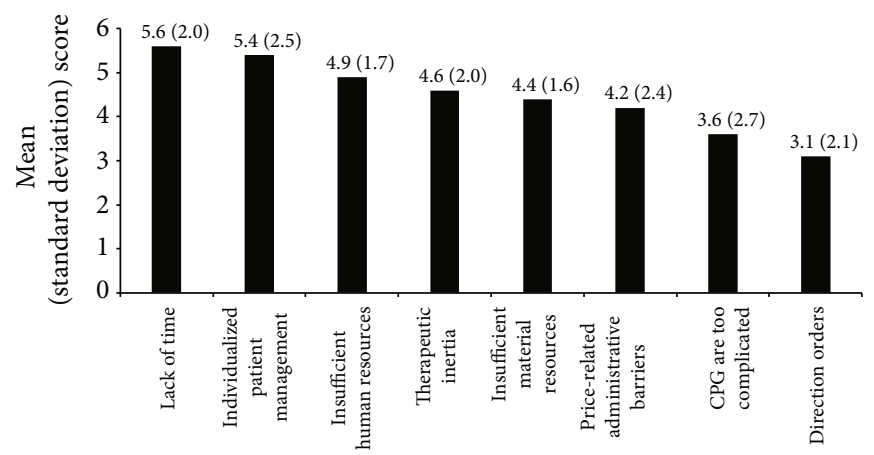

FIGURE 1: Factors related to not following recommendations of CPGs (scored from $1=$ no influence to $8=$ maximum influence; data as mean and standard deviation in parenthesis).

TABLE 1: Factors related to clinical practice guidelines (CPGs).

\begin{tabular}{|c|c|c|c|c|}
\hline \multirow[b]{2}{*}{ Items of the questionnaire } & \multirow[b]{2}{*}{ Total number } & \multicolumn{3}{|c|}{ Number of responses (\%) } \\
\hline & & $\begin{array}{l}\text { Disagree (moderately } \\
\text { disagree/strongly } \\
\text { disagree) (Likert 1-2) }\end{array}$ & $\begin{array}{l}\text { Neither agree } \\
\text { nor disagree } \\
\text { (Likert } 3 \text { ) }\end{array}$ & $\begin{array}{l}\text { Agree (moderately } \\
\text { agree/strongly agree) } \\
\text { (Likert } 4-5)\end{array}$ \\
\hline $\begin{array}{l}\text { (i) The evolution of the research, given that sometimes } \\
\text { there are subsequent findings that are proven uncertain } \\
\text { or irreproducible, may reduce the credibility of the CPG } \\
\text { recommendations }\end{array}$ & 96 & $20(20.8)$ & $5(5.2)$ & $71(74.0)$ \\
\hline $\begin{array}{l}\text { (ii) The complexity of the process recommended in the } \\
\text { CPG difficults adherence }\end{array}$ & 96 & $48(50.0)$ & $6(6.3)$ & $42(43.8)$ \\
\hline $\begin{array}{l}\text { (iii) Scientific advances organized in the form of } \\
\text { guidelines and recommendations are an invaluable help } \\
\text { for clinicians }\end{array}$ & 98 & $2(2.0)$ & $2(2.0)$ & $94(95.9)^{*}$ \\
\hline $\begin{array}{l}\text { (iv) The objective of the guidelines is to provide an up- } \\
\text { to-date informative framework that helps the clinician to } \\
\text { make the most appropriate decisions individually for } \\
\text { each patient }\end{array}$ & 98 & $3(3.0)$ & $1(1.0)$ & $94(95.9)^{*}$ \\
\hline $\begin{array}{l}\text { (v) The dynamic nature of scientific knowledge implies } \\
\text { the periodic reassessment of the CPGs }\end{array}$ & 98 & $2(2.0)$ & 0 & $96(97.9)^{*}$ \\
\hline $\begin{array}{l}\text { (vi) An effective dissemination of the CPGs and their } \\
\text { updates is necessary }\end{array}$ & 98 & $2(2.0)$ & 0 & $96(97.9)^{*}$ \\
\hline $\begin{array}{l}\text { (vii) There are different CPGs whose recommendations } \\
\text { do not coincide }\end{array}$ & 96 & $13(13.6)$ & $6(6.3)$ & $77(80.2)^{\dagger}$ \\
\hline $\begin{array}{l}\text { (viii) Although a guide is well implemented it is difficult } \\
\text { to maintain it, since after a certain time professionals } \\
\text { tend to return to their previous routines }\end{array}$ & 96 & $66(68.8)$ & $6(6.3)$ & $24(25.0)$ \\
\hline $\begin{array}{l}\text { (ix) It is crucial to incorporate adherence indicators to } \\
\text { the CPGs }\end{array}$ & 96 & $4(4.2)$ & $6(6.3)$ & $86(89.6)^{\dagger}$ \\
\hline $\begin{array}{l}\text { (x) The large number of CPGs on diabetes may prevent } \\
\text { effective dissemination }\end{array}$ & 96 & $6(6.3)$ & $4(4.2)$ & $86(89.6)^{\dagger}$ \\
\hline
\end{tabular}

${ }^{*}$ Consensus achieved in the first Delphi round; ${ }^{\dagger}$ consensus achieved in the second Delphi round.

adherence to CPGs" as one factor related to diabetes (Table 3); "therapeutic inertia favors continuation with previous practice," "constant updates of the CPGs make it difficult to be up to date and have a deep knowledge of them," and "professionals must handle complex pharmacological treatment, which is perceived as a difficulty for intensification" as three factors related to the clinician (Table 3); and "complexity of treatment difficults therapeutic adherence" as one factor related to the patient (Figure 2). Moreover, ther- apeutic inertia was not significantly correlated with the lack of time in consultation $(\rho=0.002 ; P=0.983)$.

\section{Discussion}

This two-round Delphi study was conducted to explore the level of adherence to CPGs for T2DM by Spanish endocrinologists and to identify barriers associated with nonadherence. Different characteristics of participants enhance the 
TABLE 2: Factors related to the healthcare system and the healthcare center.

\begin{tabular}{|c|c|c|c|c|}
\hline \multirow[b]{2}{*}{ Items of the questionnaire } & \multirow[b]{2}{*}{ Total number } & \multicolumn{3}{|c|}{ Number of responses (\%) } \\
\hline & & $\begin{array}{l}\text { Disagree (moderately } \\
\text { disagree/strongly } \\
\text { disagree) (Likert 1-2) }\end{array}$ & $\begin{array}{l}\text { Neither agree } \\
\text { nor disagree } \\
\text { (Likert 3) }\end{array}$ & $\begin{array}{l}\text { Agree (moderately } \\
\text { agree/strongly agree) } \\
\text { (Likert 4-5) }\end{array}$ \\
\hline \multicolumn{5}{|l|}{ Healthcare system-related factors } \\
\hline $\begin{array}{l}\text { (i) The limitations to the prescription established by } \\
\text { the public healthcare system prevent treatment } \\
\text { according to the CPG }\end{array}$ & 96 & $18(18.7)$ & $3(6.3)$ & $72(75.0)^{\dagger}$ \\
\hline $\begin{array}{l}\text { (ii) Differences in administrative limitations of local } \\
\text { authorities between autonomous communities may } \\
\text { have a different impact on adherence to CPGs }\end{array}$ & 98 & $4(4.1)$ & $5(5.1)$ & $89(90.9)^{*}$ \\
\hline $\begin{array}{l}\text { (iii) Recommendations of international CPGs generally } \\
\text { do not coincide with the current situation of our } \\
\text { healthcare system }\end{array}$ & 96 & $45(46.9)$ & $10(10.4)$ & $41(42.7)$ \\
\hline \multicolumn{5}{|l|}{ Healthcare center-related factors } \\
\hline $\begin{array}{l}\text { (i) The clinician does not have enough time in the care } \\
\text { of his/her patients to follow some recommendations }\end{array}$ & 96 & $4(4.1)$ & $3(3.1)$ & $89(92.7)^{\dagger}$ \\
\hline $\begin{array}{l}\text { (ii) There are no adequate material resources for the } \\
\text { diagnosis and treatment recommended in the CPG }\end{array}$ & 96 & $30(31.3)$ & $14(14.6)$ & $52(54.2)$ \\
\hline $\begin{array}{l}\text { (iii) There are not adequate human resources for the } \\
\text { diagnosis and treatment recommended in the CPG }\end{array}$ & 96 & $10(10.4)$ & $3(3.1)$ & $83(86.5)^{\dagger}$ \\
\hline
\end{tabular}

${ }^{*}$ Consensus achieved in the first Delphi round; ${ }^{\dagger}$ consensus achieved in the second Delphi round.

TABLE 3: Factors related to diabetes and the clinician.

\begin{tabular}{|c|c|c|c|c|}
\hline \multirow[b]{2}{*}{ Items of the questionnaire } & \multirow[b]{2}{*}{ Total number } & \multicolumn{3}{|c|}{ Number of responses $(\%)$} \\
\hline & & $\begin{array}{l}\text { Disagree (moderately } \\
\text { disagree/strongly } \\
\text { disagree) (Likert 1-2) }\end{array}$ & $\begin{array}{l}\text { Neither agree } \\
\text { nor disagree } \\
\text { (Likert } 3)\end{array}$ & $\begin{array}{l}\text { Agree (moderately } \\
\text { agree/strongly agree) } \\
\text { (Likert } 4-5)\end{array}$ \\
\hline \multicolumn{5}{|l|}{ Diabetes-related factors } \\
\hline $\begin{array}{l}\text { (i) The complexity of the pathology makes it difficult to } \\
\text { be compliant with the CPG }\end{array}$ & 96 & $61(63.5)$ & $11(11.5)$ & $24(25.0)$ \\
\hline $\begin{array}{l}\text { (ii) The risk of hypoglycemia continues to be a limiting } \\
\text { factor for the comprehensive control of patients with } \\
\text { diabetes }\end{array}$ & 96 & $12(12.5)$ & $4(4.2)$ & $80(83.4)^{\dagger}$ \\
\hline \multicolumn{5}{|l|}{ Clinician-related factors } \\
\hline $\begin{array}{l}\text { (i) Therapeutic inertia means that despite knowing the } \\
\text { CPG recommendations, the clinician continues with his } \\
\text { previous practice }\end{array}$ & 96 & $12(12.5)$ & $4(4.2)$ & $80(83.3)^{\dagger}$ \\
\hline $\begin{array}{l}\text { (ii) The constant updates of the CPGs make it difficult to } \\
\text { be up to date and have a deep knowledge of them }\end{array}$ & 96 & $28(29.2)$ & $8(8.3)$ & $60(62.5)$ \\
\hline $\begin{array}{l}\text { (iii) Professionals must handle complex pharmacological } \\
\text { treatment, which is perceived as a difficulty for } \\
\text { intensification }\end{array}$ & 96 & $24(25.0)$ & $12(12.5)$ & $60(62.5)$ \\
\hline $\begin{array}{l}\text { (iv) The lack of connection between all the members of } \\
\text { the interdisciplinary team that manages diabetes makes } \\
\text { access to new agents and combined therapies difficult }\end{array}$ & 96 & $23(23.9)$ & $10(10.4)$ & $63(65.6)$ \\
\hline $\begin{array}{l}\text { (v) It would be necessary to have the support of } \\
\text { dietitians and podiatrists in the management of patients } \\
\text { with T2DM }\end{array}$ & 98 & $1(1.0)$ & $3(3.1)$ & $94(95.9)^{*}$ \\
\hline $\begin{array}{l}\text { (vi) The insufficient number of nursing personnel with } \\
\text { specific training in diabetes education makes it difficult } \\
\text { to approach patients with T2DM }\end{array}$ & 98 & $2(2.0)$ & $2(2.0)$ & $94(95.9)^{*}$ \\
\hline
\end{tabular}

${ }^{*}$ Consensus achieved in the first Delphi round; ${ }^{\dagger}$ consensus achieved in the second Delphi round. 


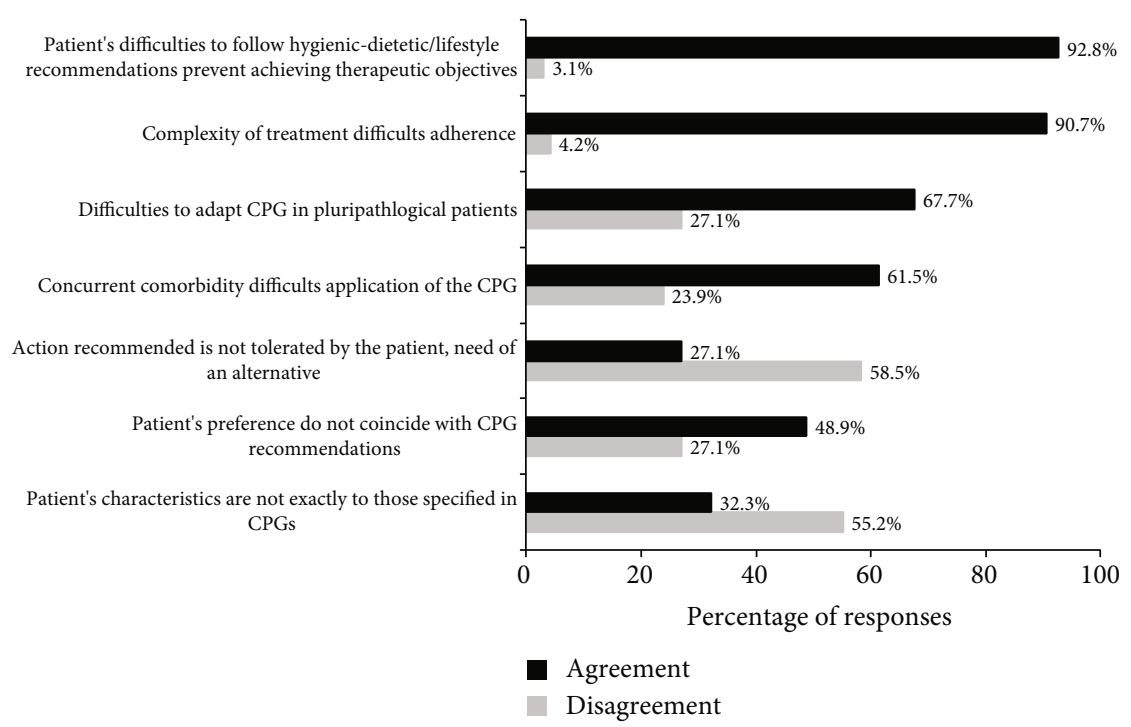

FIGURE 2: Factors related to the patient preventing adherence to recommendations of CPGs (5-point Likert scale; agree: moderately/strongly agree (scores 4-5), disagree: moderately/strongly disagree (scores 1-2).

value of their responses, including a wide range of age (mean 45 years), large experience (mean 16 years), tertiary care hospitals from the public health care system and large specialized services (median 9 endocrinologist) as the working setting, and high percentage of endocrinologists who reported participation in training programs of diabetes and research projects during the last year. These characteristics may explain the fact that $100 \%$ of participants were aware and used CPGs in daily practice, with ADA/EASD recommendations as the most commonly used by almost all of them, followed by recommendations of the SEEN, the AACE/ACE, and the SED. Other CPGs (NICE and Diabetes Canada) were used by only around $10 \%$ of participants. Interestingly, lack of time, individualized patient management, and insufficient human resources were three important reasons to account for nonadherence to CPGs on the endocrinologist perspective.

Although many studies have addressed compliance with metabolic and biochemical targets, blood pressure, healthy diet, physical exercise, or therapeutic recommendations in retrospective and prospective cohorts of subjects with T2DM [27-30], there is little evidence of the physicians' opinions regarding adherence and difficulties for implementing recommendations of CPGs in clinical practice. Several factors have been noted to affect the implementation and adherence to diabetic guidelines, which can be categorized in different major groups, such as factors associated with intrinsic attributes of CPGs themselves, factors related to the implementation process, physician's and patient's related characteristics, and factors related to the organization of the healthcare system [24].

From the perspective of intrinsic features of guidelines, there was a consistent agreement on the advantages of their use, particularly, to support appropriate decisions in individual patients, the need to update information regularly, and the importance of incorporating adherence indicators in the CPGs. In relation to factors associated with clinicians, consensus was achieved regarding insufficient human resources with support on the part of nursing personnel, dietitians, and podiatrists, as well as the risk of hypoglycemia as a limiting factor for the control of patients and the negative role of therapeutic inertia. Therapeutic inertia impairs the ability of to attain and maintain glycemic targets, which in turn increases risks for the development and progression of diabetes-related complications. Therapeutic inertia has been identified as an important contributor to failure to advance or deintensify treatment, although in a broader concept clinical inertia includes also issues such as failure to screen, make appropriate referrals, and manage risk factors and complications [31]. In a systematic review of 53 studies of therapeutic inertia in the treatment of hyperglycemia in patients with T2DM, the median time to treatment intensification after a HbA1c measurement above target was more than 1 year. Therapeutic inertia increased as the number of antidiabetic drugs rose and decreased with increasing HbA1c levels [32]. In a retrospective analysis using electronic medical records from 23,678 patients with $\mathrm{HbAlc} \geq 7 \%$ and a first prescription for a new noninsulin antidiabetic drug or insulin recorded from January 2010 to December 2014, in Catalonia, Spain, intensification was not undertaken in 1 in 5 patients, with a median time to first intensification of 17.1 months [33].

In a study to assess adherence to German treatment guidelines for T2DM with the participation of 46 experienced physicians, they had a consistent perspective on the value of the national treatment guidelines, but perceived patient inability and demotivation to be the strongest adherence barriers [22]. In the present study, complexity of treatment and patient's difficulties to follow hygienic-dietetic/lifestyle recommendations was remarkable barriers preventing adherence to CPGs. Concurrent comorbidity and pluripathology were also limiting factors. Another interesting finding of the study was the absence of significant differences according to age of the participants, which may indicate that neither age nor the years of experience might have an impact on the causes of nonadherence to CPGs. 
The present results should be interpreted taking into account the observational and exploratory nature of the survey based on self-reporting, reflecting the subjective perception of the participants. However, the number of participants was almost 100, and all of them were endocrinologists with a solid experience in type 2 diabetic patients care; so, the survey was able to capture a broad set of perspectives of adherence barriers related to the guidelines, healthcare system, physicians, and patients. It is, to our knowledge, the first assessment of physician perspective on T2DM guideline adherence in the Spanish-speaking area.

\section{Conclusions}

Nonadherence to CPGs on T2DM is a multifactorial problem but the existence of multiple CPGs, the lack of time, the therapeutic inertia, and the complexity of diabetes has been identified as factors limiting adherence. Hypoglycemia continues to be a barrier for achievement of targets recommended by CPGs. Increasing the number of healthcare professionals in the multidisciplinary teams (diabetes specialist nurses, dietitians, and podiatrists) is necessary in providing good patient care and promoting adherence to CPGs.

\section{Data Availability}

The data used to support the findings of this study are available from the corresponding author upon request.

\section{Conflicts of Interest}

The authors declare that they have participated as speakers and meetings supported by Novo-Nordisk as well as advisory boards with Novo-Nordisk.

\section{Authors' Contributions}

All authors participated in the development of the study protocol, study questionnaire, discussion of the results, and drafting of the manuscript. All authors have seen and approved the final manuscript.

\section{Acknowledgments}

The authors thank Grupo Saned, S.L., for logistic and statistical support and Marta Pulido, MD, PhD, for editing the manuscript and editorial assistance. This study was founded by Novo Nordisk España, Madrid, Spain.

\section{Supplementary Materials}

\section{(Supplementary Materials)}

\section{References}

[1] J. L. Harding, M. E. Pavkov, D. J. Magliano, J. E. Shaw, and E. W. Gregg, "Global trends in diabetes complications: a review of current evidence," Diabetologia, vol. 62, no. 1, pp. 3-16, 2019.
[2] A. Alzaid, P. Ladrón de Guevara, M. Beillat, V. Lehner Martin, and P. Atanasov, "Burden of disease and costs associated with type 2 diabetes in emerging and established markets: systematic review analyses," Expert Review of Pharmacoeconomics \& Outcomes Research, 2020.

[3] T. Seuring, O. Archangelidi, and M. Suhrcke, "The economic costs of type 2 diabetes: a global systematic review," PharmacoEconomics, vol. 33, no. 8, pp. 811-831, 2015.

[4] S. Wild, G. Roglic, A. Green, R. Sicree, and H. King, "Global prevalence of diabetes: estimates for the year 2000 and projections for 2030," Diabetes Care, vol. 27, no. 5, pp. 1047-1053, 2004.

[5] E. A. Nyenwe, T. W. Jerkins, G. E. Umpierrez, and A. E. Kitabchi, "Management of type 2 diabetes: evolving strategies for the treatment of patients with type 2 diabetes," Metabolism, vol. 60, no. 1, pp. 1-23, 2011.

[6] American Diabetes Association, "Standards of medical care in Diabetes-2020Abridged for primary care providers," Clin Diabetes., vol. 38, no. 1, pp. 10-38, 2020.

[7] F. Cosentino, P. J. Grant, V. Aboyans et al., "2019 ESC guidelines on diabetes, pre-diabetes, and cardiovascular diseases developed in collaboration with the EASD," European Heart Journal, vol. 41, no. 2, pp. 255-323, 2020.

[8] National Health Institute for Health and Care Excellence (NICE), Type 2 diabetes in adults: management, NICE guideline, 2021, https://www.nice.org.uk/guidance/ng28.

[9] Diabetes Canada, New 2018 guidelines, 2021, http://guidelines diabetes.ca/cpg.

[10] SED Sociedad Española de Diabetes, Recomendaciones de la Sociedad Española de Diabetes (SED) para el tratamiento farmacológico de la hiperglucemia en la diabetes tipo 2, Actualización 2018, 2021, https://www.sediabetes.org/.

[11] R. Reyes-García, Ó. Moreno-Pérez, C. Tejera-Pérez et al., "Document on a comprehensive approach to type 2 diabetes mellitus," Endocrinología, Diabetes y Nutrición, vol. 66, no. 7, pp. 443-458, 2019.

[12] M. S. Kirkman, S. R. Williams, H. H. Caffrey, and D. G. Marrero, "Impact of a program to improve adherence to diabetes guidelines by primary care physicians," Diabetes Care, vol. 25, no. 11, pp. 1946-1951, 2002.

[13] C. M. Renders, G. D. Valk, L. V. Franse, F. G. Schellevis, J. T. van Eijk, and G. van der Wal, "Long-term effectiveness of a quality improvement program for patients with type 2 diabetes in general practice," Diabetes Care, vol. 24, no. 8, pp. 13651370, 2001.

[14] R. Gross, H. Tabenkin, A. Porath et al., "The relationship between primary care physicians' adherence to guidelines for the treatment of diabetes and patient satisfaction: findings from a pilot study," Family Practice, vol. 20, no. 5, pp. 563$569,2003$.

[15] F. Muzaffar, N. Fatima, A. Fawwad, and M. Riaz, "Adherence of healthcare professionals to American Diabetes Association 2004 guidelines for the care of patients with type 2 diabetes at peripheral diabetes clinics in Karachi, Pakistan," Pakistan Journal of Medical Sciences, vol. 29, no. 2, pp. 474-478, 2013.

[16] F. McCrate, M. Godwin, and L. Murphy, "Attainment of Canadian Diabetes Association recommended targets in patients with type 2 diabetes: a study of primary care practices in St John's, Nfld," Nfld. Can Fam Physician., vol. 56, no. 1, pp. e13-e19, 2010. 
[17] L. M. Renard, V. Bocquet, G. Vidal-Trecan, M. L. Lair, and C. Blum-Boisgard, "Adherence to international follow-up guidelines in type 2 diabetes: a longitudinal cohort study in Luxembourg," PLoS One, vol. 8, no. 11, article e80162, 2013.

[18] G. Worrall, D. Freake, J. Kelland, A. Pickle, and T. Keenan, "Care of patients with type II diabetes: a study of family physicians' compliance with clinical practice guidelines," The Journal of Family Practice, vol. 44, no. 4, pp. 374-381, 1997.

[19] L. Casanova, A. Bocquier, S. Cortaredona et al., "Membership in a diabetes-care network and adherence to clinical practice guidelines for treating type 2 diabetes among general practitioners: A four- year follow-up," Primary Care Diabetes, vol. 10, no. 5, pp. 342-351, 2016.

[20] N. G. Bimpas, V. Auyeung, A. Tentolouris, E. Tzeravini, I. Eleftheriadou, and N. Tentolouris, "Adoption of and adherence to the Hellenic diabetes association guidelines for the management of subjects with type 2 diabetes mellitus by Greek physicians," Hormones (Athens, Greece), vol. 20, no. 2, 2021.

[21] J. H. Barth, S. Misra, K. M. Aakre et al., "Why are clinical practice guidelines not followed?," Clinical Chemistry and Laboratory Medicine, vol. 54, no. 7, pp. 1133-1139, 2016.

[22] S. Brenner, W. Oberaigner, and H. Stummer, "In guidelines physicians trust? Physician perspective on adherence to medical guidelines for type 2 diabetes mellitus," Heliyon., vol. 6, no. 8, article e04803, 2020.

[23] Y. Chen, F. A. Sloan, and A. P. Yashkin, "Adherence to diabetes guidelines for screening, physical activity and medication and onset of complications and death," Journal of Diabetes and its Complications, vol. 29, no. 8, pp. 1228-1233, 2015.

[24] N. R. Hashmi and S. A. Khan, "Adherence to diabetes mellitus treatment guidelines from theory to practice: the missing link," Journal of Ayub Medical College, Abbottabad, vol. 28, no. 4, pp. 802-808, 2016.

[25] G. Skulmoski, F. Hartman, and J. Krahn, "The Delphi method for graduate research," Journal of Information Technology Education, vol. 6, pp. 1-21, 2007.

[26] F. T. Hartman and A. Baldwin, "Using technology to improve Delphi method," Journal of Computing in Civil Engineering, vol. 9, no. 4, pp. 244-249, 1995.

[27] C. L. Lai and Y. H. Hou, "The association of clinical guideline adherence and pay-for-performance among patients with diabetes," Journal of the Chinese Medical Association, vol. 76, no. 2, pp. 102-107, 2013.

[28] S. W. Oh, H. J. Lee, H. J. Chin, and J. I. Hwang, "Adherence to clinical practice guidelines and outcomes in diabetic patients," International Journal for Quality in Health Care, vol. 23, no. 4, pp. 413-419, 2011.

[29] A. Kuznik and J. Mardekian, "Trends in utilization of lipidand blood pressure-lowering agents and goal attainment among the U.S. diabetic population, 1999-2008," Cardiovascular Diabetology, vol. 10, no. 1, 2011.

[30] M. S. Faulkner and S. F. Michaliszyn, "Exercise adherence in Hispanic adolescents with obesity or type 2 diabetes," Journal of Pediatric Nursing, vol. 56, pp. 7-12, 2021.

[31] S. L. Karam, J. Dendy, S. Polu, and L. Blonde, "Overview of therapeutic inertia in diabetes: prevalence, causes, and consequences," Diabetes Spectrum: A Publication of the American Diabetes Association, vol. 33, no. 1, pp. 8-15, 2020.
[32] K. Khunti, M. B. Gomes, S. Pocock et al., "Therapeutic inertia in the treatment of hyperglycaemia in patients with type 2 diabetes: a systematic review," Diabetes, Obesity \& Metabolism, vol. 20, no. 2, pp. 427-437, 2018.

[33] M. Mata-Cases, J. Franch-Nadal, J. Real et al., "Therapeutic inertia in patients treated with two or more antidiabetics in primary care:Factors predicting intensification of treatment," Diabetes, Obesity \& Metabolism, vol. 20, no. 1, pp. 103-112, 2018. 